\title{
Análisis de mezclas de residuos sólidos orgánicos empleadas en la fabricación de ladrillos ecológicos no estructurales
}

\author{
Analysis of Organic Solid Waste Mixtures Used in the Manufacture of Non- \\ structural Ecological Bricks \\ Ruth Sánchez-Bernal ${ }^{1}$, Diber Jeannette Pita-Castañeda ${ }^{2}$, \\ Krystle Danitza González-Velandia ${ }^{3}$, Jhonatan Andrés Hormaza-Verdugo ${ }^{4}$
}

[Recibido: 19 junio 2018, Aceptado: 11 de setiembre 2018, Corregido: 6 de noviembre 2018, Publicado: 1 de enero 2019]

\section{Resumen}

Frente a la necesidad de generar estrategias para el aprovechamiento de residuos sólidos orgánicos en espacios reducidos que mitiguen su contaminación al ambiente, en esta investigación se evaluó la viabilidad del aprovechamiento de residuos orgánicos en la elaboración de ladrillos ecológicos no estructurales, mediante el análisis del comportamiento de parámetros fisicoquímicos con diferentes mezclas de residuos sólidos orgánicos. En la primera etapa de la investigación se trataron seis mezclas en procesos de compostaje aerobio y anaerobio, de las cuales se seleccionaron las dos que tardaron más tiempo en el proceso de biodegradación con el pH establecido por la normatividad. En la siguiente fase, las dos mezclas seleccionadas se encapsularon dentro de los ladrillos de tierra y se analizaron durante 45 días, posteriormente se seleccionó la mezcla de menor pérdida de masa para ser nuevamente encapsulada en el ladrillo durante un periodo de 3 meses. La biomasa resultante se sometió a análisis fisicoquímicos y se encontró que es viable el uso de residuos sólidos orgánicos encapsulados en los ladrillos de tierra no estructurales.

Palabras clave: Biomasa interna; compostaje; parámetros fisicoquímicos; residuos sólidos orgánicos.

\begin{abstract}
Faced with the need to generate strategies for the use of organic solid waste in small spaces that mitigate their pollution to the environment, this research evaluated the feasibility of using organic waste in the production of non-structural ecological bricks, by analyzing the behavior of physicochemical parameters under different mixtures of organic solid waste. In the first stage of the investigation, six were mixed in aerobic and anaerobic composting processes, of which the two that took the longest time in the biodegradation process with the $\mathrm{pH}$ established by the

1 Ingeniera agrónoma, con especialidad en Gestión de Proyectos. Profesional de Proyectos de la Escuela de Ingeniería Social, Corporación Universitaria Minuto de Dios, Sede Principal, Bogotá, Colombia, ruth.sanchez@uniminuto.edu, ORCID: 0000-0003-0911-1666.

2 Licenciada en Biología y Química, con especialidad en Educación y Gestión Ambiental, candidata a Máster en Educación Ambiental. Coordinadora de Proyectos de la Escuela de Ingeniería Social, Corporación Universitaria Minuto de Dios, Sede Principal, Bogotá, Colombia. dpita@uniminuto.edu. ORCID: 0000-0002-7346-1487.

3 Ingeniera Agrícola, con Magíster en Gestión Ambiental y Desarrollo Sostenible. Docente investigadora de la Facultad de Ingeniería, Corporación Universitaria Minuto de Dios, Sede Principal. Bogotá, Colombia, kgonzalez@uniminuto.edu, ORCID: 0000-0002-6982-2569.

4 Ingeniero Agroecólogo. Egresado de la Corporación Universitaria Minuto de Dios, Sede Principal. Bogotá, Colombia. jhormaz3@uniminuto.edu.co. ORCID: 0000-0001-9479-5200.
\end{abstract}

(c) (i)

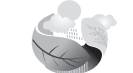

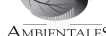

AMBIENAALS

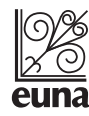

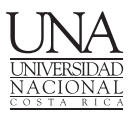




\section{Revista de CIENCIAS AMBIENTALES Tropical Journal of Environmental Sciences}

Revista de Ciencias Ambientales (Trop J Environ Sci). ElSSN: 2215-3896. (Enero-Junio, 2019) . Vol 53(1): 23-44. Dol: http://dx.doi.org/10.15359/rca.53-1.2 Open Access: www.revistas.una.ac.cr/ambientales EMAIL: revista.ambientales@una.ac.cr Sánchez-Bernal R., Pita-Castañeda D. J., González-Velandia K. D., Hormaza-Verdugo J. A.

regulations were selected. In the next phase, the two selected mixtures were encapsulated inside the earthen bricks and analyzed for 45 days, after which the mixture with the lowest mass loss was selected to be re-encapsulated in the brick for three months. The resulting biomass was subjected to physicochemical analysis finding that the use of organic solid waste encapsulated in nonstructural bricks is viable.

Keywords: Internal biomass; composting; physical-chemical parameters; organic solid waste.

\section{Introducción}

Un problema ambiental que enfrentan la mayoría de urbes en el mundo, y en particular Latinoamérica, es poder gestionar y disponer adecuadamente de la gran cantidad de residuos sólidos urbanos producidos (García y Toro, 2000). Esta situación es evidente al observar desechos tirados en las afueras de las ciudades, en los cauces de los ríos o cuando son enterrados sin ninguna consideración técnica.

En Colombia, según la "Superintendencia de Servicios Públicos Domiciliarios (2015) para el año 2014, se generaron 13.8 millones de toneladas de residuos sólidos urbanos y rurales" (Consejo Nacional de Política Económica y Social [CONPES], 2016, p. 9), de los cuales el 61.5 \% son residuos orgánicos (CONPES, 2016, p. 41). En Bogotá, el 53.22 \% de los residuos que llegan diariamente al relleno sanitario Doña Juana corresponden a residuos orgánicos (Alcaldía Mayor de Bogotá y Universidad Nacional de Colombia, 2014).

A lo anterior, se suma el tratamiento insuficiente que se realiza a los residuos en la fuente. Este consiste, principalmente, en la recolección, el transporte y la disposición final en el relleno sanitario, donde son depositados y posteriormente enterrados. De no realizarse las modificaciones necesarias, los costos para la ciudad de Bogotá serán altos y difíciles de corregir (Alcaldía Mayor de Bogotá y Universidad Nacional de Colombia, 2014; Anzola, 2015).

En Bogotá, y en Colombia también, los residuos sólidos orgánicos son los que más se producen y los que menos se aprovechan. Esto incrementa la contaminación en medios receptores como el suelo, el agua o el aire; tiene consecuencias directas en el paisaje; produce gases de efecto invernadero que contribuyen al problema del cambio climático $\mathrm{y}$, en algunos casos, se convierten en vectores de plagas.

Se han desarrollado diferentes tecnologías para el aprovechamiento de los residuos orgánicos. Por ejemplo, el compostaje y lombricultivo permiten transformar estos residuos en abono que luego se reincorpora al ciclo productivo (Alcaldía Mayor de Bogotá y Universidad Nacional de Colombia, 2014). Con el mismo propósito se han desarrollado las pacas digestoras, en las que se encapsula rastrojo y material orgánico seco con residuos orgánicos frescos, donde, por medio de un proceso anaerobio, se transforman en abono (Ardila, Cano, Silva, \& López, 2015). Otro ejemplo son los biodigestores, tecnología que permite aprovechar el gas metano que producen estos residuos para generación de energía (Marti, 2007; Pedraza, Chará, Conde, Giraldo, y Giraldo, 2002). Desafortunadamente, estas tecnologías de aprovechamiento de residuos orgánicos son poco implementadas en ambientes citadinos, en algunos casos por falta de espacio físico adecuado.

\begin{tabular}{|c|c|c|}
\hline 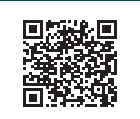 & (c) (i) (\$) () & 24 \\
\hline
\end{tabular}


Basada en el panorama mencionado, esta investigación se planteó como objetivo evaluar la viabilidad del aprovechamiento de residuos orgánicos en la elaboración de ladrillos ecológicos no estructurales, con el fin de que contribuyan a la mitigación de los impactos negativos generados por la inadecuada disposición de estos en la ciudad. Se analizó cuál de las mezclas o biomasas de residuos orgánicos presentan el mejor comportamiento de biodegradación para ser empleadas en los ladrillos ecológicos, de tal manera que sea factible como tecnología que aporte al manejo adecuado de los residuos orgánicos en la ciudad, sin destinar grandes áreas de terreno.

\section{Marco teórico}

\subsection{Métodos de descomposición de la biomasa interna}

Los métodos utilizados en la descomposición de la biomasa interna se fundamentan en la técnica de compostaje, basados en función de la descomposición de los residuos orgánicos, esta es aeróbica o anaeróbica. La Unidad Administrativa Especial de Servicios Públicos [UAESP] (2010) define el compostaje como:

la intervención humana dentro del proceso natural de descomposición de la materia orgánica con una combinación de condiciones ambientales apropiadas y un tiempo adecuado. Dicho de otra manera, es un proceso bioxidativo controlado, en el que intervienen numerosos y variados microorganismos, que requiere una humedad adecuada y sustratos orgánicos heterogéneos en estado sólido, y que produce al final de los procesos de degradación, dióxido de carbono $\left(\mathrm{CO}_{2}\right)$, agua y minerales, así como una materia orgánica estabilizada, libre de fitotoxinas, dispuesta para su empleo en agricultura sin que provoque fenómenos adversos. (p.122)

La descomposición aeróbica o aerobia es el proceso que ocurre en presencia de oxígeno, el cual es realizado mediante aireaciones periódicas que aceleran el trabajo de bacterias y microorganismos aeróbicos que descomponen la materia orgánica por oxidación; los residuos generados en la descomposición aeróbica son $\mathrm{CO}_{2}$, agua, y biomasa (Lugo, 1998; Román, Martínez y Pantoja 2013). Alternativamente, en la descomposición anaeróbica, el proceso se realiza totalmente cubierto y sucede en ausencia de oxígeno, donde los microorganismos anaeróbicos son quienes descomponen la materia orgánica por reducción, y producen, en esta descomposición, $\mathrm{CO}_{2}$, una pequeña cantidad de biomasa y un volumen considerable de gas metano (Lugo, 1998; Román et al., 2013).

\subsection{Característica físico-químicas de los residuos sólidos orgánicos}

Según la normativa colombiana se considera residuo sólido a:

\begin{tabular}{|c|c|c|}
\hline 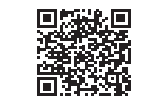 & (c) (i) (9) () () & 25 \\
\hline
\end{tabular}




\section{Revista de CIENCIAS AMBIENTALES Tropical Journal of Environmental Sciences}

Revista de Ciencias Ambientales (Trop J Environ Sci). EISSN: 2215-3896. (Enero-Junio, 2019) . Vol 53(1): 23-44. D0l: http://dx.doi.org/10.15359/rca.53-1.2 Open Access: www.revistas.una.ac.cr/ambientales EMAIL: revista.ambientales@una.ac.cr

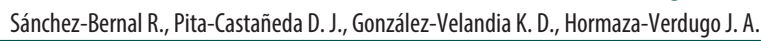

cualquier objeto, material, sustancia o elemento principalmente sólido resultante del consumo o uso de un bien en actividades domésticas, industriales, comerciales, instituciones o de servicios, que el generador presenta para su recolección por parte de la persona prestadora del servicio público de aseo; igualmente, se considera como residuo sólido, aquel proveniente del barrido y limpieza de áreas y vías públicas, corte de césped y poda de árboles. (CONPES, 2016, p. 63)

Dentro de los residuos se encuentran los residuos orgánicos. Estos se clasifican según su naturaleza o característica física en residuos de alimentos, estiércol, restos vegetales, papel y cartón, cuero, plásticos biodegradables (Jaramillo y Zapata, 2008); debido a las propiedades fisicoquímicas y biológicas, dichos residuos son ideales para el proceso de compostaje por la rápida descomposición (De la Cruz, 2008). En las investigaciones realizadas por la UAESP (2011a, 2011b), se estimó la media ponderada de la composición química de residuos sólidos degradables residenciales y comerciales de pequeños grupos productores de la Ciudad de Bogotá (Cuadro 1), y se estableció que el porcentaje de humedad y el $\mathrm{pH}$ de la masa degradable se encuentran dentro de los rangos recomendados para el aprovechamiento de estos residuos en procesos de compostaje, además la concentración de metales pesados está por debajo de los límites máximos establecido por la norma técnica colombiana NTC 5167.

Cuadro 1. Media ponderada de la composición química de masa degradable ${ }^{\star}$ de residuos sólidos residenciales y comerciales de pequeños productores de la ciudad de Bogotá en el año 2011

\begin{tabular}{|c|c|c|c|c|}
\hline \multirow[b]{2}{*}{ Componente } & \multirow[b]{2}{*}{ Expresado en } & \multirow[b]{2}{*}{ Residenciales } & \multicolumn{2}{|c|}{ Comerciales pequeños productores por actividad } \\
\hline & & & Bienes y servicios & Alimentos y bebidas \\
\hline Humedad total & $\%$ & 67.18 & 53.29 & 63.86 \\
\hline Ceniza & $\%$ & 4.04 & 6.10 & 8.31 \\
\hline Pérdidas por volatilización & $\%$ & 25.75 & 40.61 & 27.83 \\
\hline Nitrógeno orgánico & $\%$ & 0.58 & 0.86 & 1.04 \\
\hline $\begin{array}{l}\text { Carbono orgánico Oxidable } \\
\text { total }\end{array}$ & $\%$ & 10.31 & 17.26 & 11.31 \\
\hline Relación $\mathrm{C} / \mathrm{N}$ & & 23.71 & 20.60 & 11.00 \\
\hline $\mathrm{pH}$ & & 5.69 & 6.50 & 6.30 \\
\hline \multicolumn{5}{|l|}{ Metales pesados } \\
\hline -Arsénico & Ppm & 1.00 & 1.00 & 1.00 \\
\hline -Cadmio & Ppm & 0.18 & 0.60 & 0.60 \\
\hline -Cromo & Ppm & 2.93 & 8.40 & 2.50 \\
\hline -Mercurio & Ppm & 1.00 & 1.00 & 1.00 \\
\hline -Níquel & Ppm & 2.16 & 3.70 & 1.50 \\
\hline -Plomo & Ppm & 2.86 & 10.30 & 4.10 \\
\hline
\end{tabular}

* Masa degradable es una muestra representativa de los residuos orgánicos: alimentos, jardín, madera, textil, papel y carbón. ppm: partes por millón (g/Kg). Fuente: elaborado a partir de UAESP (2011a, 2011b).

\begin{tabular}{|c|c|c|}
\hline 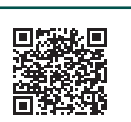 & (c) (i) () (2) & 26 \\
\hline
\end{tabular}


Dentro de los residuos orgánicos se seleccionan los que se producen localmente, con base en aquellos utilizados en la elaboración de compostaje, teniendo en cuenta principalmente sus propiedades fisicoquímicas. Estas son:

- Residuos de alimentos no preparados como cáscaras y demás restos vegetales, cuya aproximación de la composición se describe en el Cuadro 1.

- Ceniza, se compone de óxidos como el óxido de sílice $\left(\mathrm{SiO}_{2}\right)$, de hierro $\left(\mathrm{Fe}_{2} \mathrm{O}_{3}\right)$, de calcio $(\mathrm{CaO})$, de magnesio $(\mathrm{MgO})$, de potasio $\left(\mathrm{K}_{2} \mathrm{O}\right)$, de fósforo $\left(\mathrm{P}_{2} \mathrm{O}_{5}\right)$ y de azufre $\left(\mathrm{SO}_{3}\right)$, con $\mathrm{pH}$ alcalinos con valores superiores a 8 , empleada en el mejoramiento del $\mathrm{pH}$ en suelos ácidos, y ayuda a los microorganismos en la descomposición de la materia (Cárdenas, 2009).

- Cuncho o poso de café, contiene celulosa, lignina y nutrientes naturales como nitrógeno $(\mathrm{N})$, fósforo $(\mathrm{P})$, potasio $(\mathrm{K})$, calcio $(\mathrm{Ca})$, magnesio $(\mathrm{Mg})$ y azufre $(\mathrm{S})$, contribuyen a la proliferación de micro y macro fauna como hongos y lombrices (Gaitán, Salmones, Pérez, y Mata, 2006; Ritoré, 2012).

- Residuos de flores como hojas, pétalos y tallos; tienen celulosa, lignina, contenidos de humedad entre 65.3 y 90 \% (González, Daza, Caballero, y Martínez, 2016). Según Jiménez (2006, citado por Tituaña, 2009, p. 19) presentan baja relación de carbono - nitrógeno (C/N) entre 12.5 y 14.8 .

- Cascarilla de arroz es un sustrato orgánico de baja tasa de descomposición, liviano, de buen drenaje, con tejido de lenta degradación, sus principales sustancias son la lignina y la sílice en forma de $\mathrm{SiO}_{2}$, por su alta tasa de aireación se incorpora como parte de la mezcla del compostaje (Sierra, 2009).

- Suelo o tierra, las características físico-químicas como biológicas del suelo varían de acuerdo con el sitio de donde se extrae; sin embargo, por lo general presenta una granulometría equilibrada, características físicas que permiten el arreglo de las partículas y de los poros, lo cual mejora la aireación, la retención y movimiento del agua, ideal para el uso en la agricultura y en la construcción (Karlena, Ditzlerb, y Andrews, 2003; Rivera, 2012).

\section{Metodología}

Para la determinación de la biomasa interna final en la elaboración de ladrillos ecológicos no estructurales se desarrolló el siguiente proceso metodológico:

\begin{tabular}{|c|c|c|}
\hline 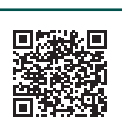 & (c) (1) () (2) & 27 \\
\hline
\end{tabular}




\subsection{Definición de las mezclas de la biomasa interna de los ladrillos no estructurales ecológicos}

Para la definición de las combinaciones de la biomasa interna para la elaboración de ladrillos no estructurales ecológicos se seleccionaron los residuos sólidos orgánicos referenciados en el Cuadro 2. Luego, se estableció la relación $\mathrm{C} / \mathrm{N}$ de las diferentes mezclas con base en el cálculo de proporcionalidad (Román et al., 2013, pp. 53-54), obteniendo la proporción de cada residuo, la cual se convirtió en porcentaje. Para este cálculo, también se tuvo en cuenta que la relación C/N de las mezclas fuese cercana al 30:1, según lo indicado por Román et al. (2013).

Cuadro 2. Residuos orgánicos seleccionados según las mezclas de biomasa interna de los ladrillos no estructurales ecológicos

\begin{tabular}{|c|c|c|c|c|c|c|}
\hline Residuos sólidos orgánicos & Mezcla 1 & Mezcla 2 & Mezcla 3 & Mezcla 4 & Mezcla 5 & Mezcla 6 \\
\hline Suelo & $\mathrm{X}$ & $\mathrm{X}$ & $\mathrm{X}$ & $\mathrm{X}$ & $\mathrm{X}$ & $\mathrm{X}$ \\
\hline Ceniza & $\mathrm{X}$ & & $\mathrm{X}$ & $\mathrm{X}$ & $\mathrm{X}$ & \\
\hline Hojarasca seca & $\mathrm{X}$ & & & & & \\
\hline Residuos de alimentos* & $\mathrm{X}$ & $\mathrm{X}$ & $\mathrm{X}$ & $\mathrm{X}$ & & $\mathrm{X}$ \\
\hline Cáscara de naranja & & & & & $\mathrm{X}$ & \\
\hline Cascarilla de arroz & & & & $\mathrm{X}$ & & $\mathrm{X}$ \\
\hline Corte de pasto & & & & & $\mathrm{X}$ & $\mathrm{X}$ \\
\hline Viruta & & $\mathrm{X}$ & & & & \\
\hline Corona de piña & & & & $\mathrm{X}$ & & \\
\hline Tallos de flores & & & & $\mathrm{X}$ & & \\
\hline Cuncho de café & & $\mathrm{X}$ & & $\mathrm{X}$ & & $\mathrm{X}$ \\
\hline Servilleta & & & $\mathrm{X}$ & & & \\
\hline
\end{tabular}

* Residuos de alimentos no preparados

Los residuos orgánicos necesarios en las mezclas de las biomasas internas fueron acopiados en la cocina del Hogar Infantil Semillas de Mostaza, la plaza de mercado de Quirigua, un mercado fruver, asaderos de pollo y arepas, cafeterías, ubicados en la localidad de Engativá (Bogotá D.C.). De estos se tomó una muestra para evaluar las siguientes propiedades físicas:

- Tamaño del residuo: mide la longitudinal, el diámetro transversal mayor y la profundidad. Para el caso de residuos orgánicos de alimentos sin preparar, pasto y papel se tomaron los cálculos después de ser picados.

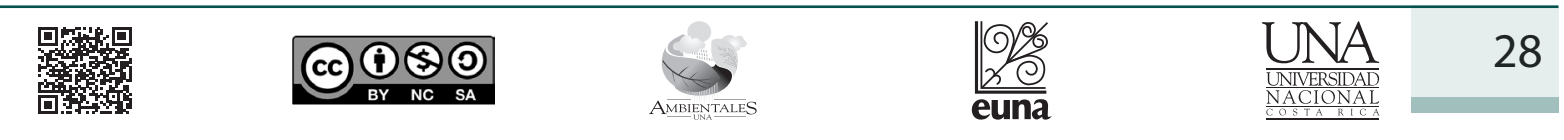




\section{Revista de CIENCIAS AMBIENTALES Tropical Journal of Environmental Sciences}

Revista de Ciencias Ambientales (Trop J Environ Sci). EISSN: 2215-3896.

(Enero-Junio, 2019) . Vol 53(1): 23-44. D0l: http://dx.doi.org/10.15359/rca.53-1.2 Open Access: www.revistas.una.ac.cr/ambientales EMAlL: revista.ambientales@una.ac.cr

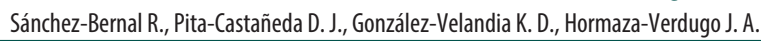

- Contenido de humedad $(\mathrm{CH})$ : relación entre la cantidad de agua que posee cada residuo y su masa seca, se utiliza el método de cuantificación de humedad descrito en la norma técnica colombiana NTC 5167 (Instituto Colombiano de Normas Técnicas y Certificación [INCONTEC], 2004, pp. 8-9).

- Porosidad: basada en la relación de la densidad real y densidad aparente.

La medición de estos parámetros se realizó con tres pedazos de cada residuo y los datos obtenidos se promediaron.

\subsection{Prueba piloto}

En esta prueba se prepararon las seis mezclas con la composición resultante en la definición de las combinaciones de la biomasa interna, adicionando a cada una $30 \%$ de arena con el fin de que disminuya la pérdida de masa. Además, se reguló el contenido de humedad, alrededor del $60 \%$, por medio de la prueba de puño cerrado (Román et al., 2013).

Las mezclas de las biomasas internas fueron dispuestas en recipientes de madera forrados en el interior con plástico, acoplando en una esquina una manguera conectada a un contenedor para la recolección de lixiviados. Los tratamientos para todas las mezclas fueron compostaje aerobio con tres repeticiones; y compostaje anaerobio, para el caso de esta investigación sin volteo, con tres repeticiones para las mezclas 1, 3, 4 y 5 y dos repeticiones para las mezclas 2 y 6 .

A las mezclas en proceso de compostaje aerobio se les garantizó mayor aireación mediante volteos, tres veces por semana. Al total de las biomasas se les realizó el seguimiento y registro de los parámetros fisicoquímicos durante el proceso de descomposición como se describe a continuación:

- Apreciación cualitativa: revisión semanalmente sobre la evolución de las biomasas en términos de cambios en olores, colores y presencia de animales.

- Lixiviados generados: medición de la cantidad de líquidos (en volumen) liberados en el contendor durante el proceso de compostaje.

- Temperatura interna: medido tres veces por semana, con termómetro de punta de lectura instantánea.

- $\mathrm{pH}$ : determinado semanalmente, con un pHmetro.

\begin{tabular}{|c|c|c|}
\hline 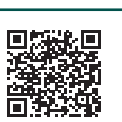 & (c) (1) () () () & 29 \\
\hline
\end{tabular}




\section{Revista de CIENCIAS AMBIENTALES Tropical Journal of Environmental Sciences}

Revista de Ciencias Ambientales (Trop J Environ Sci). EISSN: 2215-3896.

(Enero-Junio, 2019) . Vol 53(1): 23-44.

DOl: http://dx.doi.org/10.15359/rca.53-1.2

Open Access: www.revistas.una.ac.cr/ambientales

EMAlL: revista.ambientales@una.ac.cr Sánchez-Bernal R., Pita-Castañeda D. J., González-Velandia K. D., Hormaza-Verdugo J. A.

- $\mathrm{CH}$ : se determina al final del proceso de biodegradación, mediante la cuantificación de humedad, método descrito en la NTC 5167.

- Tiempo de biodegradación del total de los residuos orgánicos: el tiempo del proceso de compostaje de las mezclas de biomasa interna debe superar los 2 meses.

Los datos colectados fueron analizados mediante comparación con los criterios descritos en el Cuadro 3. A los parámetros de $\mathrm{pH}$ y contenido de humedad se les efectuó análisis de la varianza con un intervalo de confianza del $95 \%$, para lo cual se utilizó Microsoft Excel.

Cuadro 3. Parámetros y condiciones a cumplir para la definición de las biomasas internas a encapsular en la carcasa de los ladrillos ecológicos no estructurales

\begin{tabular}{ll}
\hline \multicolumn{1}{c}{ Parámetros a caracterizar } & \multicolumn{1}{c}{ Condiciones a cumplir } \\
\hline Apreciación cualitativa & $\begin{array}{l}\text { Sin generación de olores desagradables, ni presencia de animales durante el pro- } \\
\text { ceso de compostaje. }\end{array}$ \\
& $\begin{array}{l}\text { Colores similares al suelo (entre cafés y negro) al final del proceso de biodegra- } \\
\text { dación. }\end{array}$ \\
Lixiviados & Sin generación de lixiviados durante el proceso de compostaje \\
Temperatura interna & Temperatura similar a la del ambiente al final del proceso de biodegradación \\
Potencial de hidrógeno $(\mathrm{pH})$ & pH mayor de 4 y menor de 9 durante el proceso de compostaje. \\
Contenido de humedad $(\mathrm{CH})$ & Máximo 35 al final del proceso de biodegradación. \\
$\begin{array}{l}\text { Tiempo de biodegradación del total de los } \\
\text { residuos orgánicos }\end{array}$ & El tiempo del proceso del compostaje supera los 2 meses. \\
\hline
\end{tabular}

Fuente: elaborado a partir de INCONTEC (2004) y Román et al. (2013).

\subsection{Prueba de la biomasa interna en los ladrillos ecológicos no estructurales}

En esta prueba, las mezclas de biomasa interna de los resultados obtenidos de la prueba piloto fueron encapsuladas en la carcasa de los ladrillos ecológicos en tierra no estructurales; se elaboraron doce ladrillos. A los 45 días de la fabricación, para la definición de la biomasa interna final, se tomaron 3 muestras de biomasa en proceso de biodegradación, y se evaluaron los parámetros de $\mathrm{pH}$, apreciación cualitativa determinados como se indicó en la prueba piloto; contenido de nitrógeno en forma de nitratos, amonio y nitritos con el KIT de suelos LAMOTTE, método factible para la medición de propiedades del suelo, y pérdida de masa. A los datos colectados de los parámetros de $\mathrm{pH}$ y pérdida de masa obtenidos se les estimaron el promedio y el análisis de varianza con un intervalo de confianza del $95 \%$.

Tres meses después de la elaboración de los ladrillos se les determinó parámetros físicos, químicos y biológicos a 2 muestras de biomasa interna final; los métodos empleados para la

\begin{tabular}{|c|c|c|}
\hline 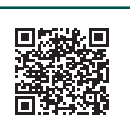 & (c) (1) (9) () () & 30 \\
\hline
\end{tabular}




\section{Revista de CIENCIAS AMBIENTALES Tropical Journal of Environmental Sciences}

Revista de Ciencias Ambientales (Trop J Environ Sci). EISSN: 2215-3896. (Enero-Junio, 2019) . Vol 53(1): 23-44. D0l: http://dx.doi.org/10.15359/rca.53-1.2 Open Access: www.revistas.una.ac.cr/ambientales EMAlL: revista.ambientales@una.ac.cr Sánchez-Bernal R., Pita-Castañeda D. J., González-Velandia K. D., Hormaza-Verdugo J. A.

caracterización se mencionan en el Cuadro 4. Los resultados se analizan mediante la comparación con los indicadores de calidad sugeridos en la norma NTC 5167 y la Norma Técnica Chilena NCh 2880.

Cuadro 4. Parámetros y métodos empleados en laboratorio para la caracterización física, química y biológica de la biomasa final

\begin{tabular}{|c|c|c|}
\hline \multicolumn{2}{|l|}{ Parámetros a caracterizar } & \multirow[t]{2}{*}{ Método } \\
\hline Indicador & Expresados en & \\
\hline Contenido de humedad & $\%$ & Cuantificación Base Húmeda \\
\hline Contenido de carbono orgánico oxidable total & $\%$ & Calcinación \\
\hline Nitrógeno $(\mathrm{N})$ amoniacal & $\%$ & Kjeldhal Base Seca \\
\hline $\mathrm{N}$ nítrico & $\%$ & Kjeldhal Base Seca \\
\hline $\mathrm{N}$ total & $\%$ & Kjeldhal Base Seca \\
\hline \multicolumn{3}{|l|}{ Relación $\mathrm{C} / \mathrm{N}$} \\
\hline $\mathrm{pH}$ & $-\log \mathrm{H}_{+}$ & Extracto de saturación \\
\hline Densidad aparente & $\mathrm{g} / \mathrm{cm}^{3}$ & \\
\hline \multicolumn{3}{|l|}{ Metales pesados: } \\
\hline -Arsénico (As) & $\mu \mathrm{g} / \mathrm{Kg}$ & Absorción atómica - Generador de hidruros \\
\hline -Cadmio (Cd) & $\mathrm{mg} / \mathrm{Kg}$ & \\
\hline -Cromo (Cr) & $\mathrm{mg} / \mathrm{Kg}$ & Digestión ácida por absorción atómica \\
\hline -Mercurio (Hg) & $\mu \mathrm{g} / \mathrm{Kg}$ & Digestión ácida por absorción atómica \\
\hline -Plomo (Pb) & $\mathrm{mg} / \mathrm{Kg}$ & Absorción atómica - Generador de hidruros \\
\hline \multicolumn{3}{|l|}{ Niveles de microorganismos patógenos: } \\
\hline -Salmonella sp & $\mathrm{UFC} / \mathrm{g}$ & Recuento en placa y LBC 205 \\
\hline -Escherichia coli & $\mathrm{UFC} / \mathrm{g}$ & Recuento en placa y LBC 205 \\
\hline -Coliformes fecales & $\mathrm{UFC} / \mathrm{g}$ & Recuento en placa \\
\hline -Coliformes totales & $\mathrm{UFC} / \mathrm{g}$ & Recuento en placa \\
\hline
\end{tabular}

UFC: Unidad Formadora de Colonias.

\section{Resultados}

\subsection{Definición de las mezclas de la biomasa interna de los ladrillos no estructurales ecológicos}

La composición de las seis mezclas de biomasa interna de los ladrillos se referencia en el Cuadro 5. La cantidad de los residuos depende del contenido de nitrógeno o carbono que estén

(cc)




\section{Revista de CIENCIAS AMBIENTALES Tropical Journal of Environmental Sciences}

Revista de Ciencias Ambientales (Trop J Environ Sci). EISSN: 2215-3896. (Enero-Junio, 2019) . Vol 53(1): 23-44. D0l: http://dx.doi.org/10.15359/rca.53-1.2 Open Access: www.revistas.una.ac.cr/ambientales EMAlL: revista.ambientales@una.ac.cr

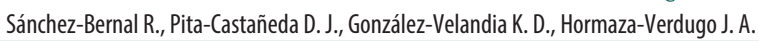

contenidos en ellos, donde los alimentos no preparados, cáscara de naranja y corte de pastos son los que aportan mayor contenido de nitrógeno, de tal manera que la relación $\mathrm{C} / \mathrm{N}$ sea cercana a 30:1.

Cuadro 5. Porcentaje de composición de las mezclas de biomasa interna de los ladrillos no estructurales ecológicos

\begin{tabular}{lcccccc}
\hline \multicolumn{1}{c}{ Residuos sólidos orgánicos } & Mezcla 1 & Mezcla 2 & Mezcla 3 & Mezcla 4 & Mezcla 5 & Mezcla 6 \\
\hline Suelo & 15 & 15 & 15 & 15 & 15 & 15 \\
Ceniza & 2 & - & 2 & 2 & 2 & - \\
Hojarasca seca & 23 & - & - & - & - & - \\
Residuos de alimentos & 60 & 71 & 75 & 50 & - & 55 \\
Cáscara de naranja & - & - & - & - & 41 & - \\
Cascarilla de arroz & - & - & - & 14 & & 16 \\
Corte de pasto & - & - & - & - & - & 10 \\
Viruta & - & - & - & - & - & - \\
Corona de piña & - & - & - & 7 & - & - \\
Tallos de flores & - & - & - & 9 & - & - \\
Cuncho de café & - & 5 & - & 3 & - & - \\
Servilleta & - & - & 8 & & -
\end{tabular}

* Residuos de alimentos no preparados

La caracterización física de los residuos orgánicos urbanos se describe en el Cuadro 6. El contenido de humedad y la porosidad depende del tipo de residuo, los tallos de flores son los residuos orgánicos urbanos (RSU) empleados en la biomasa interna que presentan mayor tamaño de residuo y contenido de humedad, mientras que la ceniza es la que contiene mayor porosidad, sin humedad.

Cuadro 6. Caracterización de propiedades físicas de los residuos sólidos orgánicos urbanos utilizados en la biomasa interna final

\begin{tabular}{|c|c|c|c|c|c|}
\hline \multirow[b]{2}{*}{ Residuos orgánicos } & \multicolumn{3}{|c|}{ Tamaño del residuo } & \multirow{2}{*}{$\begin{array}{c}\begin{array}{c}\text { Contenido } \\
\text { humedad } \\
(\%)\end{array} \\
\end{array}$} & \multirow{2}{*}{$\begin{array}{l}\text { Porosidad } \\
(\%)\end{array}$} \\
\hline & $\begin{array}{l}\text { Longitud } \\
(\mathrm{cm})\end{array}$ & $\begin{array}{l}\text { Diámetro transversal } \\
(\mathrm{cm})\end{array}$ & $\begin{array}{c}\text { Profundidad } \\
(\mathrm{cm})\end{array}$ & & \\
\hline Tallos flores & 3.55 & 0.63 & 0.46 & 87 & 61.29 \\
\hline $\begin{array}{l}\text { Residuos de alimentos no } \\
\text { preparados }\end{array}$ & 2.42 & 0.49 & 0.14 & 84 & 32.68 \\
\hline Cuncho café & 0.05 & 0.09 & 0.08 & 71 & 36.18 \\
\hline Ceniza & - & - & - & 0 & 79.86 \\
\hline Suelo & - & - & - & 44 & 45.89 \\
\hline
\end{tabular}

\subsection{Seguimiento de parámetros fisicoquímicos en la prueba piloto}

En el seguimiento de los parámetros fisicoquímicos en el proceso de compostaje en las 6 mezclas planteadas (Cuadro 5), al inicio de este, las mezclas 2 y 3 aerobias y anaerobias

\begin{tabular}{|c|c|}
\hline 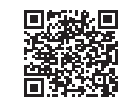 & (c) (1) (5) () () \\
\hline
\end{tabular}




\section{Revista de CIENCIAS AMBIENTALES Tropical Journal of Environmental Sciences}

Revista de Ciencias Ambientales (Trop J Environ Sci). EISSN: 2215-3896. (Enero-Junio, 2019) . Vol 53(1): 23-44. DOl: http://dx.doi.org/10.15359/rca.53-1.2 Open Access: www.revistas.una.ac.cr/ambientales EMAlL: revista.ambientales@una.ac.cr

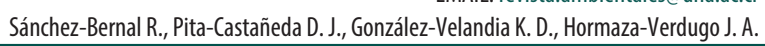

presentaron olores fuertes similares a la putrefacción; se realizó como correctivo la adición de ceniza y volteo diario de las mezclas, tres días después en la mezcla 2 desapareció el olor. Se repite dos veces más el correctivo en la mezcla 3, pero continúa la presencia del olor, sumado a la aparición y aumento de larvas de mosca, por lo cual, se descarta la mezcla 3 tanto aerobia, como anaerobia. El resto de las mezclas durante el proceso de compostaje no presentaron emisión de olores.

En relación con la generación de lixiviados, en la mezcla 6 anaerobia se presentó durante las dos primeras semanas. El resto de las mezclas no produjeron lixiviados durante todo el proceso.

La temperatura en el total de las mezclas no alcanzó el incremento ideal de la etapa termófila del proceso de compostaje. Las temperaturas máximas de las mezclas fueron: de $28^{\circ} \mathrm{C}$ para las mezclas 1 y 4 , de $29^{\circ} \mathrm{C}$ para la mezcla 2 , de $30^{\circ} \mathrm{C}$ para la mezcla 5 y de $27^{\circ} \mathrm{C}$ para la mezcla 6 .

Durante el proceso de compostaje, en la mezcla 5 el corte de pasto, correspondiente al 40 $\%$ de la combinación, formó bolas, lo que no permitió la descomposición de este residuo. En la semana 12 los residuos orgánicos de la mezcla 2 estaban totalmente degradados; la hojarasca, tallos de flores y cascarilla de arroz en las mezclas 1, 4 y 6 no habían terminado su trasformación; esto resulta importante para la definición de la biomasa final, debido a que una de las características que se desean es que el tiempo de compostaje supere los 2 meses.

Al final del proceso de compostaje el pH es alcalino (Cuadro 7), con una certeza del $95 \%$ la media del pH final en las mezclas 1, 2, 4, 5 y 6 se encuentran en intervalo de $\mathrm{pH}$ entre 8.2 y 10.6 para el compostaje anaerobio y pH entre 8.4 y 10.2 para la aerobia. Según Bueno, Díaz, y Cabrer (s. f.), si el pH se mantiene por encima de 7.5 durante el proceso de compostaje, es síntoma de una buena descomposición. La media del contenido de humedad final $(\mathrm{CH})$ en todas mezclas se encuentra en el rango permitido por NTC 5167 (Cuadro 7).

Cuadro 7. Media del pH y $\mathrm{CH}$ de las mezclas de la biomasa interna, finalizado el proceso de compostaje durante la prueba piloto

\begin{tabular}{ccccc}
\hline \multirow{2}{*}{ Mezcla } & \multicolumn{2}{c}{ Compostaje anaerobio } & \multicolumn{2}{c}{ Compostaje aerobio } \\
\cline { 2 - 5 } & $\mathrm{pH}$ & $\mathrm{CH}(\%)$ & $\mathrm{pH}$ & $\mathrm{CH}(\%)$ \\
\hline $\mathbf{1}$ & 9.9 & 9.41 & 9.9 & 13.51 \\
$\mathbf{2}$ & 9.2 & 8.17 & 9.5 & 10.49 \\
$\mathbf{4}$ & 8.9 & 7.26 & 9.0 & 11.58 \\
5 & 9.4 & 12.47 & 10.0 & 6.73 \\
6 & 7.8 & 10.60 & 8.2 & 8.45 \\
\hline
\end{tabular}

Con base en lo anterior, se definen las mezclas 4 y 6 para ser encapsuladas como parte integral del ladrillo ecológico no estructural, debido a que el tiempo de degradación del total de los residuos de tallos de flor y cascarilla de arroz superan los dos meses (Cuadro 3) y el pH se encuentra dentro de los valores propuestos en la NTC 5167. Además, según los resultados de la apreciación cualitativa y el lixiviado durante el proceso de compostaje cumplen con las condiciones propuestas para la definición (Cuadro 3).

\begin{tabular}{|c|c|c|}
\hline 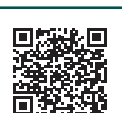 & (c) (i) () () () & 33 \\
\hline
\end{tabular}




\subsection{Comportamiento de biomasa interna en los ladrillos ecológicos no estructurales}

Durante el seguimiento de parámetros fisicoquímicos al proceso de compostaje de las biomasas internas, mezclas 4 y 6, encapsuladas como parte del ladrillo ecológico no estructural, los lixiviados y olores desagradables presentaron igual comportamiento que la prueba piloto en relación con que estaban ausentes. Además, la temperatura no alcanzó la etapa termófila: la temperatura máxima de $18.2^{\circ} \mathrm{C}$ para mezcla 4 y de $17.6{ }^{\circ} \mathrm{C}$ para la mezcla 6 .

A los 45 días de construidos los ladrillos ecológicos no estructurales, visualmente en las dos mezclas no se identificaron los residuos orgánicos provenientes de alimentos no preparados, la ceniza y el cuncho de café, por lo cual se afirma que presentaron proceso de descomposición. Mientras que, a los residuos de tallo de flores, corona de piña, corte de pasto y cascarilla de arroz les falta biodegradación, evidenciado por su forma y tamaño similar al adicionado, aunque perdieron el color y estaban deshidratados.

En este mismo tiempo la media del pH fue alcalina (Cuadro 8); según el análisis de varianza, con una significancia del $5 \%$, no hay diferencias significativas en las medias del pH entre las repeticiones de cada biomasa interna (mezclas 4 y 6), ni entre los dos tipos de biomasas internas encapsuladas en los ladrillos (Apéndice 1).

Cuadro 8. Media de parámetros físico-químicos de las biomasas internas dentro de la carcasa del ladrillo, tomados a los 45 días

\begin{tabular}{ccccc}
\hline Mezcla & $\mathbf{p H}$ & $\begin{array}{c}\text { Pérdida de masa } \\
(\mathbf{g})\end{array}$ & $\begin{array}{c}\text { Contenido nitritos } \\
(\mathbf{p p m})\end{array}$ & $\begin{array}{c}\text { Contenido amonio } \\
(\mathbf{p p m})\end{array}$ \\
\hline 4 & 9.87 & 13.26 & 1 & Muy bajo \\
6 & 9.73 & 73.94 & $<1$ & Muy Bajo \\
\hline
\end{tabular}

Los resultados del análisis de varianza (Apéndice 2), con una significancia del 5\%, permiten determinar que no se registraron diferencias significativas en la pérdida de masa entre las repeticiones de cada biomasa interna (mezclas 4 y $6, \mathrm{p}=0.585$ ), pero sí hay diferencias significativas entre las mezclas 4 y 6 de las biomasas internas encapsuladas en los ladrillos ( $\mathrm{p}=0.015)$, resulta menor la pérdida de masa en la mezcla 4 (Cuadro 8). Teniendo en cuenta esta última característica, se definió como biomasa interna final del ladrillo ecológico no estructural la mezcla 4, porque a menor pérdida de la masa se permite mejor estabilidad y permanencia al ladrillo ecológico.

La caracterización física, química y biológica de la biomasa interna final - mezcla 4 (BIF4) de dos muestras tomadas a los tres meses de encapsulamiento en la carcasa del ladrillo, se describe en el Cuadro 9.

Cuadro 9. Parámetros de la caracterización física, química y biológica de la biomasa interna final encapsulada durante tres meses en la carcasa del ladrillo ecológico no estructural

\begin{tabular}{|c|c|c|}
\hline 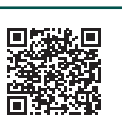 & (c) (1) () (2) & 34 \\
\hline
\end{tabular}




\section{Revista de CIENCIAS AMBIENTALES

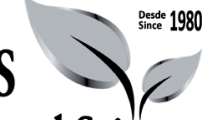 Tropical Journal of Environmental Sciences}

Revista de Ciencias Ambientales (Trop J Environ Sci). EISSN: 2215-3896. (Enero-Junio, 2019) . Vol 53(1): 23-44. Dol: http://dx.doi.org/10.15359/rca.53-1.2 Open Access: www.revistas.una.ac.cr/ambientales EMAlL: revista.ambientales@una.ac.cr Sánchez-Bernal R., Pita-Castañeda D. J., González-Velandia K. D., Hormaza-Verdugo J. A.

\begin{tabular}{|c|c|c|c|c|c|}
\hline \multirow{2}{*}{ Parámetros } & \multirow{2}{*}{ Expresado en } & \multicolumn{2}{|c|}{ Biomasa interna final } & \multirow{2}{*}{$\begin{array}{c}\text { Valor } \\
\text { recomendado }\end{array}$} & \multirow{2}{*}{ Referencia } \\
\hline & & (Muestra 4) & (Muestra 4.1) & & \\
\hline \multirow{2}{*}{ Contenido de humedad } & \multirow{2}{*}{$\%$} & \multirow{2}{*}{41.87} & \multirow{2}{*}{43.55} & Máximo 35 & NTC 5167 \\
\hline & & & & Entre 30 y 45 & NCh 2880 \\
\hline $\begin{array}{l}\text { Contenido de carbono orgánico } \\
\text { oxidable total }\end{array}$ & $\%$ & 4.3 & 4.42 & Mínimo 15 & NTC 5167 \\
\hline Nitrógeno $(\mathrm{N})$ amoniacal & $\mathrm{mg} / \mathrm{Kg}$ & 50 & 160 & $\leq 500$ & NCh 2880 \\
\hline $\mathrm{N}$ nítrico & $\%$ & 50 & 20 & & \\
\hline $\mathrm{N}$ total & $\%$ & 0.4 & 0.45 & $\geq 0,5$ & NCh 2880 \\
\hline \multicolumn{2}{|l|}{ Relación C/N } & 18.69 & 17.27 & $\begin{array}{l}\leq 25 \text { compost } \\
\text { clase } \mathrm{A}\end{array}$ & NCh 2880 \\
\hline $\mathrm{pH}$ & $-\log \mathrm{H}_{+}$ & 5.4 & 6.3 & $\begin{array}{l}\text { Mayor de } 4 \text { y } \\
\text { menor } 9\end{array}$ & NTC 5167 \\
\hline Densidad aparente & $\mathrm{g} / \mathrm{cm}^{3}$ & 0.83 & 0.68 & 0,7 & NCh 2880 \\
\hline \multirow{6}{*}{$\begin{array}{l}\text { Metales pesados: } \\
\text {-Arsénico (As) } \\
\text {-Cadmio (Cd) } \\
\text {-Cromo (Cr) } \\
\text {-Mercurio }(\mathrm{Hg}) \\
\text {-Plomo }(\mathrm{Pb})\end{array}$} & & & \multicolumn{3}{|c|}{ Máximo } \\
\hline & $\mu \mathrm{g} / \mathrm{Kg}$ & 5590.7 & 900.4 & $41 \mathrm{mg} / \mathrm{kg}$ & NTC 5167 \\
\hline & $\mathrm{mg} / \mathrm{Kg}$ & 0.6 & 0.8 & 39 & NTC 5167 \\
\hline & $\mathrm{mg} / \mathrm{Kg}$ & 96.8 & 93.2 & 1200 & NTC 5167 \\
\hline & $\mu \mathrm{g} / \mathrm{Kg}$ & 37.2 & 24.1 & $17 \mathrm{mg} / \mathrm{kg}$ & NTC 5167 \\
\hline & $\mathrm{mg} / \mathrm{Kg}$ & 28.3 & 21.9 & 300 & NTC 5167 \\
\hline \multicolumn{6}{|l|}{$\begin{array}{l}\text { Niveles de microorganismos } \\
\text { patógenos: }\end{array}$} \\
\hline \multirow{4}{*}{$\begin{array}{l}\text {-Salmonella sp } \\
\text {-Escherichia coli } \\
\text {-Coliformes fecales } \\
\text {-Coliformes totales }\end{array}$} & $\mathrm{UFC} / 25 \mathrm{~g}$ & Ausencia & Ausencia & \multirow[t]{2}{*}{ Ausente en $25 \mathrm{~g}$} & \multirow[t]{2}{*}{ NTC 5167} \\
\hline & UFC/g & Ausencia & Ausencia & & \\
\hline & $\mathrm{UFC} / \mathrm{g}$ & $<10$ & $<10$ & $<1000$ & NCh 2880 \\
\hline & $\mathrm{UFC} / \mathrm{g}$ & $<10$ & $50 \times 10^{3}$ & $<1000$ & NTC 5167 \\
\hline
\end{tabular}

Resultados en base húmeda, excepto nitrógeno total, amoniacal y nítrico, el cual es en base seca. UFC unidad formadora de colonia. NTC: norma técnica colombiana. NCh: Norma técnica chilena.

\section{Discusión}

\subsection{Definición de las mezclas de la biomasa interna de los ladrillos no estructurales ecológicos}

A excepción de la ceniza, los residuos orgánicos urbanos (RSU) empleados en la biomasa interna final presentan contenido de humedad $(\mathrm{CH})$ entre 71 al $87 \%$, humedad por encima de lo encontrado por UAESP (Cuadro 1), concordando con García, Daza y Marmolejo (2016) en que los $\mathrm{CH}$ inicial de los RSU son altos. Estos $\mathrm{CH}$ son similares a los reportados por Torres, Perez, Escobar, Uribe e Imery (2007) para los residuos orgánicos de la plaza mercado en la ciudad de Cali (71.3\%).

(c)




\section{Revista de CIENCIAS AMBIENTALES Tropical Journal of Environmental Sciences}

Revista de Ciencias Ambientales (Trop J Environ Sci). EISSN: 2215-3896.

(Enero-Junio, 2019) . Vol 53(1): 23-44.

D0l: http://dx.doi.org/10.15359/rca.53-1.2

Open Access: www.revistas.una.ac.cr/ambientales EMAlL: revista.ambientales@una.ac.cr Sánchez-Bernal R., Pita-Castañeda D. J., González-Velandia K. D., Hormaza-Verdugo J. A.

De acuerdo con lo planteado por Miyatake y Iwabuchi (2006), la humedad de la masa de compostaje debe ser tal que el agua no ocupe totalmente los poros de dicha masa, para que permita la circulación del oxígeno, debido a que el proceso debe desarrollarse en condiciones aerobias, cuando el contenido de humedad está por encima del $70 \%$, el agua desplaza al aire en los espacios libres existentes entre las partículas; por tal razón, los residuos orgánicos empleados en la mezcla de la biomasa interna final presentan humedad y porosidad diferentes (Cuadro 6), las cuales, al combinarse, distribuyen dichas características, aportando a las condiciones de aireación, en el proceso de compostaje, una vez se encapsule la biomasa de residuos orgánicos en la carcasa del ladrillo ecológico no estructural.

\subsection{Seguimiento de parámetros fisicoquímicos en la prueba piloto}

La poca descomposición del pasto en la mezcla 5 se puede atribuir a la disminución de la porosidad causada por aglutinación del pasto, que según la Alcaldía Mayor de Bogotá y Universidad Nacional de Colombia (2014) hace que el tiempo de descomposición sea más lento.

Durante el proceso de descomposición de las mezclas, estas no alcanzan la etapa termófila del proceso de compostaje, teniendo en cuenta a Román et al. (2013), ello se atribuye a la poca cantidad de residuos orgánicos necesarios para que alcance una mayor altura que permita la concentración de la temperatura al interior de la mezcla durante el proceso de compostaje. Lo anterior no afecta el objetivo de la investigación, debido a que se logra la descomposición de los RSU.

Con respecto al $\mathrm{pH}$ en las mezclas de la prueba piloto (Cuadro 7), este se encuentra entre los rangos de $\mathrm{pH}$ de la media $(\mathrm{pH}$ 7.7) y la máxima ( $\mathrm{pH} 10,2)$ reportados por Faverial, Boval, Sierra, y Sauvant (2016), lo que ratifica que el pH es uno de las parámetros que se presenta en valores cercanos a la neutralidad o alcalinidad.

Las mezclas 4 y 6, anaerobias y aerobias, presentan la media del pH final (Cuadro 7) en los niveles permitidos para productos orgánicos según la NTC 5167, es más cercana a la neutralidad la mezcla 6 anaerobia con una media pH 7.8. Según Vega (2016), el compost maduro tendrá valores de $\mathrm{pH}$ cercanos al neutro, es difícil conseguir compost con un $\mathrm{pH}$ exactamente igual a 7.0, donde en algunos casos este tiende hacia la acidez o hacia la alcalinidad, en función de los materiales dominantes durante el proceso.

\subsection{Comportamiento de biomasa interna en los ladrillos ecológicos no estructurales}

De acuerdo con los resultados descritos en el Cuadro 9, el contenido de humedad $(\mathrm{CH})$ en la BIF4 está por encima de la media obtenida durante la prueba piloto (Cuadro 7), del valor sugerido por la NTC 5167 y de los datos reportados por otros estudios en composta municipal (García et al., 2016; García, Pineda, Totosaus, y González, 2008). Al compararlos con la Norma Técnica Chilena (NCh) 2880, está dentro del rango establecido en los requisitos de calidad del compost. El alto $\mathrm{CH}$ es de importancia para el ladrillo ecológico, debido a que la humedad

\begin{tabular}{|c|c|c|c|c|c|}
\hline 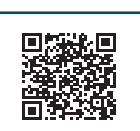 & (c) (i) (3) (2) & $\Leftrightarrow$ & 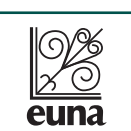 & 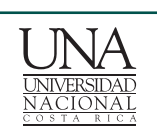 & 36 \\
\hline
\end{tabular}




\section{Revista de CIENCIAS AMBIENTALES Tropical Journal of Environmental Sciences}

Revista de Ciencias Ambientales (Trop J Environ Sci). EISSN: 2215-3896. (Enero-Junio, 2019) . Vol 53(1): 23-44. D0l: http://dx.doi.org/10.15359/rca.53-1.2 Open Access: www.revistas.una.ac.cr/ambientales EMAlL: revista.ambientales@una.ac.cr Sánchez-Bernal R., Pita-Castañeda D. J., González-Velandia K. D., Hormaza-Verdugo J. A.

retenida es necesaria para el crecimiento y desarrollo de la grama, esta última hace parte de la carcasa del ladrillo.

Con respecto al pH de la BIF4, este es menor al obtenido en la prueba piloto (Cuadro 7), y a los reportados en otros estudios (Daza, 2014; García et al., 2008; Torres et al., 2007), se encuentra dentro del rango establecido por la NTC 5167. Esta variación no afecta la bidegradación de la mezcla, y se atribuye al encapsulemiento de la BIF4 en la carcasa del ladrillo ecológico.

En cuanto a los contenidos de carbono orgánico (CO) y nitrogeno total (N Total), son menores que los valores recomendados por las NTC 5167 y NCh 2880, respectivamente. Ello coincide con los hallazgo de Faverial et al. (2016) en que los compost producidos con residuos de uso doméstico y desechos sólidos municipales presentan menores contenidos de $\mathrm{CO}, \mathrm{N}$ total. Dichos contenidos no son relevantes para esta investigación, ya que la función principal de los ladrillos es el aprovechamiento de los RSU.

En relación con los metales pesados, en la BIF4 solo se encontraron trazas, valores relevantes porque están por debajo de los límites máximos permitidos por NTC 5167, resultado acorde al estudio de Rojas et al. (2016) donde compara los metales pesados presentes en compost con tres normas técnicas encontrando que estos están entre los límites permisibles; y a los datos encontrados por García et al. (2008) en los análisis de cadmio y plomo presentes en una composta municipal.

Concordando con los resultados en muestras de compostaje reportados por Rojas et al. (2016) y Cekmecelioglu, Demirci, Graves, y Davitt (2005), los niveles de bacterias patógenas de BIF4 muestran ausencia de Salmonella sp y de Escherichia coli. Para Salmonella se cumple con el requisito de la NTC 5167 (Cuadro 9).

Sin embargo, la BIF4 tiene presencia de coliformes fecales (Cuadro 9), los cuales están por debajo de los límites permitidos en la NCh $2880^{5}$, según Yanko (1988, citado por Gómez, González, y Chiroles, 2004), las muestras de compost que contengan menos de 1000 UFC/g de coliformes fecales indica que todos los microorganismos patógenos han sido destruidos, dicho plantemiento discrepa con el resultado la muestra 4.1 de la BIF4, en el cual hay contaminación con coliformes totales (valor está por encima del permitido en la NTC 5167).

Debido a lo anterior, se realiza un análisis adicional para coliformes a una muestra de la BIF4. En este se encontraron coliformes fecales $<10 \mathrm{UFC/g}$ y contaminación con coliformes totales, atribuido a que la temperatura en el proceso de compostaje no alcanzo la etapa termófila, tanto en la prueba piloto como en el seguimiento hasta los 45 días de la mezcla encapsulada en la carcasa del ladrillo.

Esta etapa del proceso de compostaje logra la eliminación de los patógenos, como sucedió en diferentes investigaciones donde el compost resultante presento el número más probable de bacterias coliformes totales por debajo del límite máximo permisible, cuyo proceso de compostaje alcanzó valores de temperatura entre 50 y $70{ }^{\circ} \mathrm{C}$ (Cekmecelioglu et al., 2005; Gómez et al., 2004; Sánchez, Zentella, y Fraire, 2015; Soares, Quina, Reis, y Quinta, 2017).

5 En la NTC 5167 el requisito niveles máximos de patógenos no referencia los coliformes fecales, por esta razón se tiene en cuenta el valor sugeridos en la NCh 2880 .

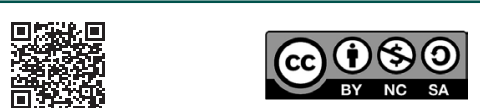
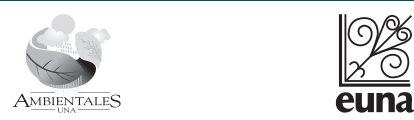

euna 


\section{Revista de CIENCIAS AMBIENTALES Tropical Journal of Environmental Sciences}

Revista de Ciencias Ambientales (Trop J Environ Sci). EISSN: 2215-3896.

(Enero-Junio, 2019) . Vol 53(1): 23-44.

D0l: http://dx.doi.org/10.15359/rca.53-1.2

Open Access: www.revistas.una.ac.cr/ambientales EMAlL: revista.ambientales@una.ac.cr Sánchez-Bernal R., Pita-Castañeda D. J., González-Velandia K. D., Hormaza-Verdugo J. A.

Aunque la BIF4 después de estar tres meses encapsulada en la carcasa del ladrillo no cumple con todos los parámetros recomendados por la NTC 5167 para el empleo como abono orgánico. De acuerdo con Soliva y López (2004 citados por García et al., 2016), los productos compostados que no cumplen con la norma se les puede dar usos, como el recubrimiento de celdas en vertederos. En el caso de los ladrillos ecológicos no estructurales la biomasa final resultante se emplea como sustrato y parte integral del ladrillo, aprovechando así los residuos sólidos orgánicos que se generen a nivel domiciliario y municipal.

\section{Conclusiones}

El proceso de descomposición de residuos sólidos orgánicos de la biomasa interna final, mezcla 4, cumplió con los parámetros y condiciones definidas para la prueba piloto: apreciación cualitativa, lixiviados, temperatura interna final, contenido de humedad y tiempo de biodegradación. Durante el encapsulamiento se presentó la menor pérdida de masa y el tiempo de descomposición del total de los residuos superior a los dos meses, condiciones indispensables para la estabilidad y durabilidad del ladrillo ecológico no estructural. La caracterización química y biológica del sustrato resultante del proceso de biodegradación de la biomasa interna final, después del encapsulamiento, muestra el $\mathrm{pH}$, el contenido de metales pesados (arsénico, cadmio, cromo, mercurio, plomo), y la presencia de Salmonella sp, en los niveles permitidos por la Norma Técnica Colombiana 5167 para productos orgánicos; además, hay ausencia de Escherichia coli. Estos factores garantizan la viabilidad del aprovechamiento de los residuos sólidos orgánicos que se generen a nivel domiciliario y municipal, mediante el encapsulamiento dentro de la carcasa del ladrillo ecológico no estructural en espacio reducidos.

Para usar el sustrato resultante del proceso de compostaje de la biomasa interna final como abono orgánico, se recomienda mayor investigación para aumentar la temperatura al interior de la biomasa debido a la presencia de coliformes fecales y coliformes totales.

\section{Agradecimientos}

Hacemos extensivo un agradecimiento al Programa de Ingeniería Agroecológica, a la Escuela de Ingeniería Social de la Facultad Ingeniería, a la doctora Mary Lucía Galindo-Galindo, y a la Dirección de Investigaciones de la Corporación Universitaria Minuto de Dios, por su contribución en esta investigación. Este estudio fue apoyado con fondos del proyecto C115-24 de la Dirección de Investigaciones del Sistema de la Corporación Universitaria Minuto de Dios. También agradecemos a la Revista y a las personas revisoras anónimas por sus oportunos comentarios que mejoraron la versión final del artículo.

\begin{tabular}{|c|c|c|}
\hline 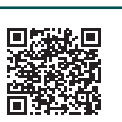 & (c) (1) () (2) & 38 \\
\hline
\end{tabular}




\section{Revista de CIENCIAS AMBIENTALES Tropical Journal of Environmental Sciences}

Revista de Ciencias Ambientales (Trop J Environ Sci). EISSN: 2215-3896. (Enero-Junio, 2019) . Vol 53(1): 23-44. D0l: http://dx.doi.org/10.15359/rca.53-1.2 Open Access: www.revistas.una.ac.cr/ambientales EMAlL: revista.ambientales@una.ac.cr Sánchez-Bernal R., Pita-Castañeda D. J., González-Velandia K. D., Hormaza-Verdugo J. A.

\section{Referencias}

Alcaldía Mayor de Bogotá y Universidad Nacional de Colombia. (2014). Guía técnica para el aprovechamiento de residuos orgánicos a través de metodologías de compostaje y lombricultura. Obtenido de http://www.uaesp.gov.co/images/Guia-UAESP_SR.pdf

Anzola, D. (2015). Estudio del manejo de residuos sólidos en el Relleno Sanitario Doña Juana con el fin de delinear un borrador de propuestas para el manejo integral de residuos sólidos en la ciudad de Bogotá D.C. (Tesis de pregrado). Bogotá D.C., Colegio: Universidad Colegio Mayor de Nuestra Señora del Rosario. Obtenido de http://repository.urosario.edu.co/bitstream/ handle/10336/11399/1013622668-2015.pdf? sequence=1\&isAllowed=y

Ardila, Y., Cano, J., Silva, G., \& López, Y. (2015). Descomposción de residuos orgánicos en pacas: aspectos fisicoquímicos, biológicos, ambientales y sanitarios. Producción + Limpia, 10(2), 38-52. Obtenido de http://repository.lasallista.edu.co:8080/ojs/index.php/pl/article/ view/896/619 https://doi.org/10.22507/pml.v10n2a4

Bueno, P., Díaz, M. J., \& Cabrer, F. (s. f.). Capítulo 4. Factores que afectan al proceso de compostaje. Obtenido de http://digital.csic.es/bitstream/10261/20837/3/Factores\%20que\%20afectan\%20 al\%20proceso\%20de\%20compostaje.pdf

Cárdenas, G. (2009). Utilización de desechos del carbón: Construir a partir de las cenizas. Agencia Universitaria de Periodismo Científico. Obtenido de http://aupec.univalle.edu.co/ AUPEC/anteriores/cenizas.html

Cekmecelioglu, D., Demirci, A., Graves, R. E., \& Davitt, N. H. (2005). Optimization of windrow food waste composting to inactivate pathogenic microorganisms. Transactions of the ASAE, 48(5), 2023-2032. doi:10.13031/2013.19977

Consejo Nacional de Política Económica y Social - CONPES. (21 de Noviembre de 2016). Documento CONPES 3874: Política Nacional para la Gestión Integral de los Residuos Sólidos. Bogotá D.C., Colombia.

De la Cruz, R. (2008). Aprovechamiento de residuos orgánicos a través de composteo y lombricomposteo. México: Departamento de Fitomejoramiento. U.A.A.A.N. Obtenido de https:// es.scribd.com/document/50472521/Lombricomposta-1

Faverial, J., Boval, M., Sierra, J., \& Sauvant, D. (2016). End-product quality of composts produced under tropical and temperate climates using different raw materials: A meta-analysis. Journal of environmental management, 183, 909-916. Obtenido de https://www.sciencedirect.com/science/article/pii/S0301479716307204?via\%3Dihub

Gaitán, R., Salmones, D., Pérez, R., \& Mata, G. (2006). Manual práctico del cultivo de setas: aislamiento, siembra y producción. México: Instituto de Ecología, A.C. Obtenido de http:// www1.inecol.edu.mx/cv/CV_pdf/libros/Manual_PleurotusGaitan.pdf

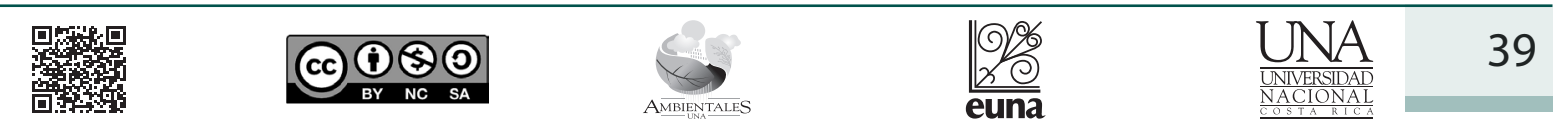




\section{Revista de CIENCIAS AMBIENTALES Tropical Journal of Environmental Sciences}

Revista de Ciencias Ambientales (Trop J Environ Sci). EISSN: 2215-3896. (Enero-Junio, 2019) . Vol 53(1): 23-44. D0l: http://dx.doi.org/10.15359/rca.53-1.2 Open Access: www.revistas.una.ac.cr/ambientales EMAIL: revista.ambientales@una.ac.cr Sánchez-Bernal R., Pita-Castañeda D. J., González-Velandia K. D., Hormaza-Verdugo J. A.

García, G., Daza, M. C., \& Marmolejo, L. F. (2016). Evaluación de la adecuación de la humedad en el compostaje de biorresiduos de origen municipal en la planta de residuos sólidos (PMRS) del Municipio de Versalles, Valle del Cauca. Gestión y Ambiente, 19(1), 179-191.

García, H., \& Toro, Z. (2000). Fundamentos del manejo de los residuos urbanos. España: Colección sénior 24. Colegio de Ingenieros de Caminos, Canales y Puertos.

García, I., Pineda, J., Totosaus, A., \& González, L. (2008). Evaluación de la presencia de metales pesados en compostas. Investigación Universitaria Multidisciplinaria, Año 7(7), 91-99.

Gómez, Y., González, M. I., \& Chiroles, S. (2004). Microorganismos presentes en el compost. Importancia de su control sanitario. Revista electrónica de la Agencia de Medio Ambiente, Año 4(2). Obtenido de http://ama.redciencia.cu/articulos/7.01.pdf

González, K., Daza, D., Caballero, P., \& Martínez, C. (2016). Evaluación de las propiedades físicas y químicas de residuos sólidos orgánicos a emplearse en la elaboración de papel. Luna Azul, 43, 499-517. doi:10.17151/luaz.2016.43.21

Instituto Colombiano de Normas Técnicas y Certificación. (Junio de 2004). Norma Técnica Colombiana NTC 5167 (Segunda actualización). Productos para la industria agrícola. Productos orgánicos usados como abonos o fertilizantes y enmiendas o acondicionadores de suelo. Obtenido de http://sian.inia.gob.ve/congresos_externos/1taller_abonos/pdf/Metodos_Analisis_Internacionales/Normas_Tecnica_Colombiana.pdf

Instituto Nacional de Normalización. (Febrero de 2005). Norma Técnica Chilena 2880: Compost, clasificación y requisitos. Obtenido de http://www.ingeachile.cl/descargas/normativa/agricola/NCH2880.pdf

Jaramillo, G., \& Zapata, L. (2008). Aprovechamiento de los residuos sólidos orgánicos en Colombia (Trabajo de Grado de Especialización). Universidad de Antioquia. Medellín, Colombia. Obtenido de http://tesis.udea.edu.co/dspace/bitstream/10495/45/1/AprovechamientoRSOUenColombia.pdf

Karlena, D. L., Ditzlerb, C. A., \& Andrews, S. S. (2003). Soil quality: why and how? Geoderma, 114, 145-156. doi:10.1016/S0016-7061(03)00039-9

Lugo, S. (1998). Evaluación de los proyectos de compostaje en el Ecuador. Obtenido de http:// www.bvsde.ops-oms.org/eswww/repamar/gtzproye/compost/compost.html

Marti, J. (2007). Experiencia de transferencia tecnológica de biodigestores familiares en Bolivia. Livestock Research for Rural Development, 19(12), Artículo 192. Obtenido de http://www.lrrd. org/lrrd19/12/mart19192.htm

\begin{tabular}{|c|c|c|}
\hline 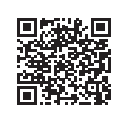 & (c) (i) $(9)$ & 40 \\
\hline
\end{tabular}




\section{Revista de CIENCIAS AMBIENTALES Tropical Journal of Environmental Sciences}

Revista de Ciencias Ambientales (Trop J Environ Sci). EISSN: 2215-3896. (Enero-Junio, 2019) . Vol 53(1): 23-44. D0l: http://dx.doi.org/10.15359/rca.53-1.2 Open Access: www.revistas.una.ac.cr/ambientales EMAIL: revista.ambientales@una.ac.cr Sánchez-Bernal R., Pita-Castañeda D. J., González-Velandia K. D., Hormaza-Verdugo J. A.

Miyatake, F., \& Iwabuchi, K. (2006). Effect of compost temperature on oxygen uptake rate, specific growth rate and enzymatic activity of microorganisms in dairy cattle manure. Bioresource Technology, Volume 97, 961-965. https://doi.org/10.1016/j.biortech.2005.04.035

Pedraza, G., Chará, J., Conde, N., Giraldo, S., \& Giraldo, L. (2002). Evaluación de los biodigestores en geomembrana (pvc) y plástico de invernadero en clima medio para el tratamiento de aguas residuales de origen porcino. Livestock Research for Rural Development, 14(1), Artículo 2. Obtenido de http://www.lrrd.cipav.org.co/lrrd14/1/Pedr141.htm

Ritoré, J. A. (20 de enero de 2012). Nace una empresa social que cultiva setas en los posos del café. [Entrada de Blog].Obtenido dehttp://blogs.lainformacion.com/laregladewilliam/2012/01/20/ nace-una-empresa-social-que-cultiva-setas-en-los-posos-del-cafe/

Rivera, J. C. (2012). El adobe y otros materiales de sistemas constructivos en tierra cruda: caracterización con fines estructurales. Apuntes, 25(2), 164 - 181. Obtenido de http://revistas. javeriana.edu.co/index.php/revApuntesArq/article/viewFile/8763/6974

Rojas, A., Vázquez, J., Romero, N., Rodríguez, M. Á., Toribio, J., \& Romero, Y. (2016). Evaluación del compost con presencia de metales pesados en el crecimietno de Azospirillum brasilence y Glomus intraradices. Mexicana de Cincia Agrícolas, 7(8), 2047-2054. Obtenido de http://www.redalyc.org/articulo.oa?id=263149505021

Román, P., Martínez, M., \& Pantoja, A. (2013). Manual de compostaje del agricultor. 2013. Experiencias en América Latina. Obtenido de http://www.fao.org/docrep/019/i3388s/i3388s.pdf

Sánchez, D., Zentella, H., \& Fraire, A. (2015). Cuantifiación de coliformes totales en las pilas de compostaje de alumnos del Instituto Tecnológico Superior de Comalcalco. Veracruz.

Sierra, J. (2009). Alternativas de aprovechamiento de la cascarilla de arroz en Colombia. (Trabajo de Grado). Universidad de Sucre. Sincelejo. Obtenido de http://repositorio.unisucre.edu.co/ bitstream/001/211/2/333.794S571.pdf

Soares, M. A., Quina, M. J., Reis, M. S., \& Quinta-Ferreira, R. (2017). Assessment of co-composting process with high load of an inorganic industrial waste. Waste Management, 59, 80-89. doi:0.1016/j.wasman.2016.09.044

Tituaña, B. (2009). Elaboración de compost mediante la inoculación de tres fuentes de microorganismos a tres dosis. Tabacundo, Pichincha (Trabajo de grado). Universidad Central del Ecuador. Quito, Ecuador. Obtenido de https://www.soiltechcorp.com/images/uploads/product_PDFs/Composting_Flower_Waste_2\%28Spanish\%29.pdf

\begin{tabular}{|c|c|c|c|c|c|}
\hline 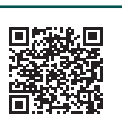 & (c) (i) () (2) (2) & $\Leftrightarrow$ & 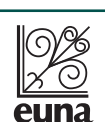 & 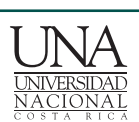 & 41 \\
\hline
\end{tabular}




\section{Revista de CIENCIAS AMBIENTALES Tropical Journal of Environmental Sciences}

Revista de Ciencias Ambientales (Trop J Environ Sci). EISSN: 2215-3896. (Enero-Junio, 2019) . Vol 53(1): 23-44. D0l: http://dx.doi.org/10.15359/rca.53-1.2 Open Access: www.revistas.una.ac.cr/ambientales EMAlL: revista.ambientales@una.ac.cr

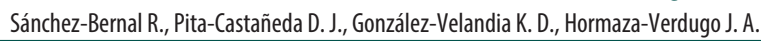

Torres, P., Perez, A., Escobar, J. C., Uribe, I. E., \& Imery, R. (2007). Compostaje de biosólidos de plantas de tratamiento de aguas residuales. Eng. Agric., Jaboticabal, 27(1), 267-275. https:// doi.org/10.1590/S0100-69162007000100021

Unidad Administrativa Especial de Servicios Públicos. (2010). Programa para la Gestión de Residuos Sólidos Orgánicos para la Ciudad de Bogotá D.C. Versión 2. Obtenido de http:// www.institutodeestudiosurbanos.info/dmdocuments/cendocieu/coleccion_digital/Metabolismo_Socioecologico_Norte/Programa_Gestion_Residuos-UAESP-2010.pdf

Unidad Administrativa Especial de Servicios Públicos. (2011). Caracterización de los residuos sólidos de establecimientos comerciales, pequeños productores, generados en la ciudad de Bogotá D.C. - 2011. Bogotá D.C., Colombia.

Unidad Administrativa Especial de Servicios Públicos. (2011). Caracterización de los residuos sólidos residenciales generados en la ciudad de Bogotá D.C. 2011. Bogotá D.C., Colombia.

Vega, J. P. (2016). Evaluación de microorganismos nativos en el proceso de degradación de materia orgánica en compostaje del Relleno Sanitario en el GAD del Cantón de la Joya de los Sachas (Tesis de pregrado). Ecuador: Escuela Superior Politécnica de Chimborazo. Obtenido de http:// dspace.espoch.edu.ec/bitstream/123456789/4949/1/236T0199.pdf

\section{Apéndices}

Apéndice 1. Análisis de varianza del pH de las biomasas interna mezcla 4 dentro de la carcasa del ladrillo, tomados a los 45 días

\begin{tabular}{lcccc}
\hline \multicolumn{1}{c}{ Resumen } & Cuenta & Suma & Promedio & Varianza \\
\hline Mezcla 4 & 3 & 29.6 & 9.867 & 0.573 \\
Mezcla 6 & 3 & 29.2 & 9.730 & 0.043 \\
pH 1 & 2 & 18.9 & 9.45 & 0.405 \\
pH 2 & 2 & 20 & 10 & 0.08 \\
pH 3 & 2 & 19.9 & 9.95 & 0.405 \\
\hline
\end{tabular}

Análisis de Varianza

\begin{tabular}{lcccccc}
\hline $\begin{array}{c}\text { Origen de las } \\
\text { variaciones }\end{array}$ & $\begin{array}{c}\text { Suma de cua- } \\
\text { drados }\end{array}$ & $\begin{array}{c}\text { Grados de } \\
\text { libertad }\end{array}$ & $\begin{array}{c}\text { Promedio de los } \\
\text { cuadrados }\end{array}$ & F & Probabilidad & $\begin{array}{c}\text { Valor crítico } \\
\text { para F }\end{array}$ \\
\hline Filas & 0.0267 & 1 & 0.0267 & 0.062 & 0.827 & 18.513 \\
Columnas & 0.370 & 2 & 0.185 & 0.428 & 0.700 & 19.000 \\
Error & 0.863 & 2 & 0.432 & &
\end{tabular}

(cC)

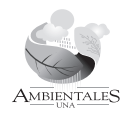




\section{Revista de CIENCIAS AMBIENTALES Tropical Journal of Environmental Sciences}

Revista de Ciencias Ambientales (Trop J Environ Sci). EISSN: 2215-3896. (Enero-Junio, 2019) . Vol 53(1): 23-44. D0l: http://dx.doi.org/10.15359/rca.53-1.2 Open Access: www.revistas.una.ac.cr/ambientales EMAlL: revista.ambientales@una.ac.cr Sánchez-Bernal R., Pita-Castañeda D. J., González-Velandia K. D., Hormaza-Verdugo J. A.

5

Apéndice 2. Análisis de varianza de la pérdida de masa de las biomasas interna mezcla 4 dentro de la carcasa del ladrillo, tomados a los 45 días

\begin{tabular}{lcccc}
\hline \multicolumn{1}{c}{ Resumen } & Cuenta & Suma & Promedio & Varianza \\
\hline Mezcla 4 & 3 & 39.77 & 13.257 & 71.613 \\
Mezcla 4 & 3 & 221.82 & 73.940 & 74.713 \\
Pérdida de Masa 1 & 2 & 75.60 & 37.800 & 1467.736 \\
Pérdida de Masa 2 & 2 & 88.47 & 44.235 & 2869.0312 \\
Pérdida de Masa 3 & 2 & 97.52 & 48.760 & 1358.247 \\
\hline
\end{tabular}

Análisis de Varianza

\begin{tabular}{lrrrrrr}
\hline $\begin{array}{c}\text { Origen de las } \\
\text { variaciones }\end{array}$ & $\begin{array}{c}\text { Suma de cua- } \\
\text { drados }\end{array}$ & $\begin{array}{c}\text { Grados de } \\
\text { libertad }\end{array}$ & $\begin{array}{c}\text { Promedio de los } \\
\text { cuadrados }\end{array}$ & F & Probabilidad & $\begin{array}{c}\text { Valor crítico } \\
\text { para F }\end{array}$ \\
\hline Filas & 5523.700 & 1 & 5523.700 & 64.486 & 0.015 & 18.5128 \\
Columnas & 121.337 & 2 & 60.669 & 0.708 & 0.585 & 19.000 \\
Error & 171.314 & 2 & 85.657 & & \\
Total & 5816.352 & 5 & & & \\
\hline
\end{tabular}




\begin{tabular}{|c|c|}
\hline $\begin{array}{l}\text { de } \\
\text { S AMBIENTALES }\end{array}$ & 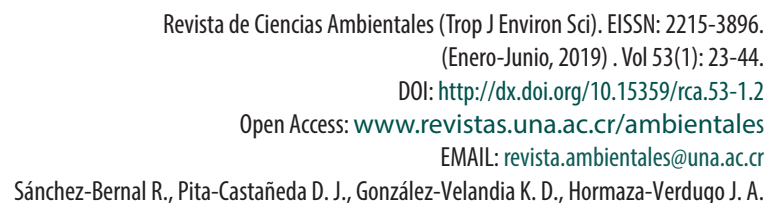 \\
\hline
\end{tabular}

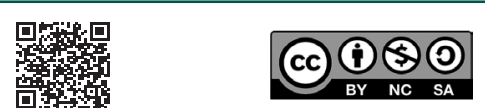

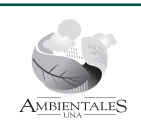

